\title{
Severity of obstructive airway disease and risk of osteoporotic fracture
}

\author{
F. de Vries*, T.P. van Staa*\#,ף, M.S.G.M. Bracke*,+, C. Cooper", \\ H.G.M. Leufkens* and J-W.J. Lammers ${ }^{+}$
}

ABSTRACT: The use of inhaled corticosteroids has been associated with a dose-related increased risk of fracture. This may be related to systemic absorption. However, several studies have found that patients with more severe reductions in pulmonary function had reduced bone mineral density, independent of inhaled corticosteroids. The objective of this study was to evaluate the relationship between disease severity and fracture risk.

A large case-control study $(\mathbf{1 0 8 , 7 5 4}$ cases) was conducted using data from the UK General Practice Research Database. It was found that higher doses of inhaled corticosteroids were associated with greater risks of fracture. The crude odds ratio of fracture among patients exposed to $>1,600 \mu \mathrm{g}$ beclomethasone equivalents per day was 1.95 (95\% confidence interval $(\mathrm{Cl}) 1.68-$ 2.27). When adjustments were made for disease severity and use of bronchodilators, the initial dose-response relationship between inhaled corticosteroids and fracture risk disappeared (adjusted odds ratio of 1.19 (95\% $\mathrm{Cl} 1.01-1.41)$ ).

In conclusion, patients with severe obstructive airway disease are at risk of fracture. However, adequate adjustment for disease severity is essential when the association between the use of inhaled corticosteroids and risk of osteoporotic fracture is studied in observational research.

KEYWORDS: Anti-inflammatory agents, bronchodilator agents, hip fractures, obstructive lung diseases, spinal fractures

I nhaled corticosteroids are frequently prescribed to patients with obstructive airway disease (OAD) [1]. Although administered locally, inhaled corticosteroids undergo systemic absorption and may induce a suppression of plasma cortisol, especially at higher doses [2]. Patients using oral corticosteroids have an increased risk of osteoporosis and fractures [3]. For users of inhaled corticosteroids, an association between daily dose and increased risk of fractures has been reported [4-7]. However, adjustment for underlying disease severity was limited in these studies. In the largest casecontrol study, adjustment for underlying disease severity was restricted to prior use of oral corticosteroids [5]. The importance of controlling for severity of underlying disease in this type of research has recently been emphasised [8, 9]. Also, it has been reported that there was no increased risk of fracture in patients using inhaled corticosteroids after adjustment for the presence of OAD [10] or use of bronchodilators [11]. Patients with OAD have been found to have a reduced bone mineral density (BMD), independent of the use of respiratory medication [12-14]. Therefore, the objective of this study was to evaluate the relationship between disease severity of OAD and the risk of fracture.

\section{METHODS \\ Study population}

A case-control study was conducted using data obtained from the General Practice Research Database (GPRD) [15]. This database comprises the entire computerised medical records of a sample of general practitioners in the UK. Several independent validation studies have confirmed a high level of completeness and validity of the GPRD with regard to the recording of fractures $[16,17]$. In this study, cases were patients aged $\geqslant 18$ yrs with a first record during GPRD followup (January 1987 to July 1999) of an osteoporotic fracture (defined as a fracture of the radius/ulna, femur/hip, ribs, humerus, vertebrae or clavicle) [18]. The date of the first fracture was defined as the index date. For each case, one control patient without a history of a fracture was matched to a case by age, sex, medical practice and calendar time. A history of OAD before the index date was examined in both cases and controls. The definitions for asthma and chronic obstructive

\section{AFFILIATIONS}

*Dept of Pharmacoepidemiology and Pharmacotherapy, Utrecht Institute for Pharmaceutical Sciences, University of Utrecht, and

${ }^{+}$Dept of Pulmonary Diseases, Utrecht Medical Center, Utrecht, The Netherlands.

\#Medical Research Council Environmental Epidemiology Unit University of Southampton, Southampton General Hospital, Southampton, and

- Procter and Gamble

Pharmaceuticals, Egham, UK.

\section{CORRESPONDENCE}

H.G.M. Leufkens

Sorbonnelaan 16

3584 CA Utrecht

The Netherlands

Fax: 310302539166

E-mail: secrfenf@pharm.uu.nl

Received

May 142004

Accepted after revision:

January 102005

SUPPORT STATEMENT

This study was supported by Procter \& Gamble Pharmaceuticals, Egham, UK. 
pulmonary disease (COPD) were the same as those used in a previous GPRD validation study [19].

\section{Definitions of variables}

Use of medication for the treatment of OAD was examined, including bronchodilators (British National Formulary (BNF) chapter 3.1 or 3.3) and inhaled corticosteroids (BNF chapter 3.2) [20]. Current users were patients who had received at least one prescription in the 6 months before the index date. Past users had received their last prescription $>6$ months prior to the index date. For each current user, the average daily dose of bronchodilators or inhaled corticosteroids was estimated by dividing the total amount of respiratory medication by the treatment time (the time between the first and last prescription of respiratory medication). Dose equivalences were expressed as beclomethasone diproprionate equivalents (inhaled corticosteroids) or salbutamol equivalents (bronchodilators). Equivalents of different compounds were calculated with defined daily doses [21].

Indicators of more severe OAD included records of OAD exacerbations and oxygen use in the 12 months before the index date, respiratory problems (bacterial respiratory tract infections, coughing, presence of sputum, haemoptysis, dyspnoea, tachypnoea, shortness of breath, acute bronchitis or wheezing), use of oral corticosteroids in the 6 months before the index date and a body mass index $(\mathrm{BMI})<20$. Next, the current authors controlled for various general risk factors of fracture, including history of diabetes mellitus, rheumatoid arthritis, hyperthyroidism, congestive heart failure, seizures, anaemia, dementia, depression, psychotic disorder and cerebrovascular accident. Moreover, prescriptions in the 6 months before the index date for anticonvulsants, nonsteroidal antiinflammatory drugs, methotrexate, hormone-replacement therapy, thiazide diuretics, anxiolytics/hypnotics, antipsychotics, antidepressants and anti-Parkinson's drugs were also considered as potential confounding variables. BMI and smoking status (current or ex-smoker, nonsmoker or unknown) were included if entered in the database.

\section{Statistical analyses}

Odds ratios (ORs) of fracture were estimated using conditional logistic regression. Final regression models were determined by backward elimination using a significance level of 0.05 . The ORs of these models were compared with the ORs of the models including all variables to identify confounding by an eliminated variable, with inclusion of this variable in cases of confounding. Current users of inhaled corticosteroids or bronchodilators with a history of OAD before the index date were compared with patients who had never been exposed to inhaled corticosteroids or bronchodilators and who did not have a diagnosis of OAD.

\section{RESULTS}

The study population included 108,754 adult patients who sustained an osteoporotic fracture (44,201 radius/ulna, 22,250 femur/hip, 16,189 rib, 14,646 humerus, 8,712 vertebral and 3,908 clavicle fractures). Baseline characteristics are listed in table 1. The median time of enrolment before the index date was 2.2 yrs. In the overall study population, higher BMI (>25) was associated with a reduced risk of a hip fracture (crude OR $0.61 ; 95 \%$ confidence interval (CI) 0.56-0.66), compared with

\section{TABLE 1 Baseline characteristics}

\begin{tabular}{|c|c|c|}
\hline Characteristics & Cases & Controls \\
\hline Subjects $n$ & 108754 & 108754 \\
\hline \multicolumn{3}{|l|}{ Age yrs } \\
\hline Mean & 62.3 & 62.3 \\
\hline Median & 66.7 & 66.8 \\
\hline Females & $71828(66)$ & $71828(66)$ \\
\hline \multicolumn{3}{|c|}{ Disease history before the index date } \\
\hline Asthma & $9172(8.4)$ & $6737(6.2)$ \\
\hline COPD & $5537(5.1)$ & $3463(3.2)$ \\
\hline Acute bronchitis & $3190(2.9)$ & $2237(2.1)$ \\
\hline Heart failure & $7586(7.0)$ & $6339(5.8)$ \\
\hline \multicolumn{3}{|c|}{ Symptoms 1 yr before the index date } \\
\hline Exacerbations & $1174(1.1)$ & $605(0.6)$ \\
\hline Difficulty with breathing & $3326(3.1)$ & 2517 (2.3) \\
\hline Wheezing & $1018(0.9)$ & $822(0.8)$ \\
\hline Coughing & $8417(7.7)$ & $6554(6.0)$ \\
\hline Respiratory infection & $1200(1.1)$ & $956(0.9)$ \\
\hline \multicolumn{3}{|c|}{ Drug use 6 months before the index date } \\
\hline One or more bronchodilators & $8213(7.6)$ & $5745(5.3)$ \\
\hline Short-acting $\beta_{2}$-agonists & $6694(6.2)$ & $4626(4.3)$ \\
\hline Antimuscarinics & $1439(1.3)$ & $829(0.8)$ \\
\hline Xanthines & $1863(1.7)$ & $1237(1.1)$ \\
\hline Long-acting $\beta_{2}$-agonists & $585(0.5)$ & $335(0.3)$ \\
\hline Inhaled corticosteroids & $5960(5.5)$ & 4107 (3.8) \\
\hline Oral corticosteroids & $5405(5.0)$ & $2989(2.7)$ \\
\hline \multicolumn{3}{|l|}{ Body mass index } \\
\hline$<20$ & $6769(6.2)$ & $4875(4.5)$ \\
\hline $20-25$ & $29088(26.7)$ & $25949(23.9)$ \\
\hline$>25$ & $28354(26.1)$ & $29550(27.2)$ \\
\hline Not determined & $44543(41.0)$ & $48380(44.5)$ \\
\hline
\end{tabular}

Data are presented as $n$ and $n$ (\%). COPD: chronic obstructive pulmonary disease.

patients with a BMI ranging 20-25. For patients with low BMI $(<20)$, the reverse was observed (crude OR 1.78; 95\% CI 1.582.00). Oral corticosteroid use was also associated with an increased risk of hip fracture (crude OR 1.75; 95\% CI 1.58-1.95). Of the cases with current oral corticosteroid use, $54 \%$ received five or more oral corticosteroid prescriptions in the previous year (for controls, this was $43 \%$ ). The percentage of patients with continuous oral corticosteroid use for $>6$ months was $44 \%$ among the cases and $36 \%$ among the controls (continuous use was defined as receiving a repeat oral corticosteroid prescription within 3 months of the previous prescription).

The risk of osteoporotic fracture was increased in patients with asthma (crude OR 1.28; 95\% CI 1.23-1.32), in patients with COPD (crude OR 1.61; 95\% CI 1.52-1.71), and in patients who had both diagnoses recorded (crude OR 1.72; 95\% CI 1.601.85). Patients with an indicator of more severe OAD generally had increased risks of fracture (fig. 1) compared with patients without the indicator who did not have a history of OAD. For example, the risk of osteoporotic fracture among patients with OAD exacerbations was 2.02 (95\% CI 1.82-2.23) and 2.54 (95\% CI 1.90-3.40) among patients with a BMI <20. Patients with OAD who also smoked had an increased risk of osteoporotic 
a) Respiratory symptoms 6 months prior

Oral-steroid use 6 months prior

Exacerbation(s)

12 months prior

Oxygen use

12 months prior

Body mass index $<20$

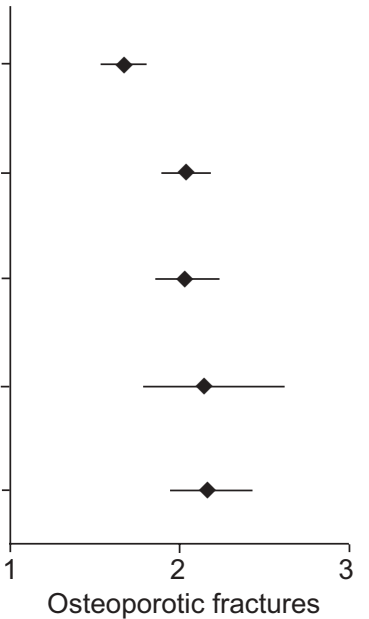

b)

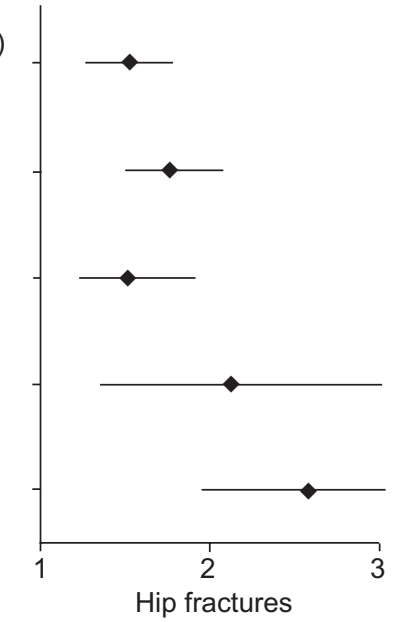

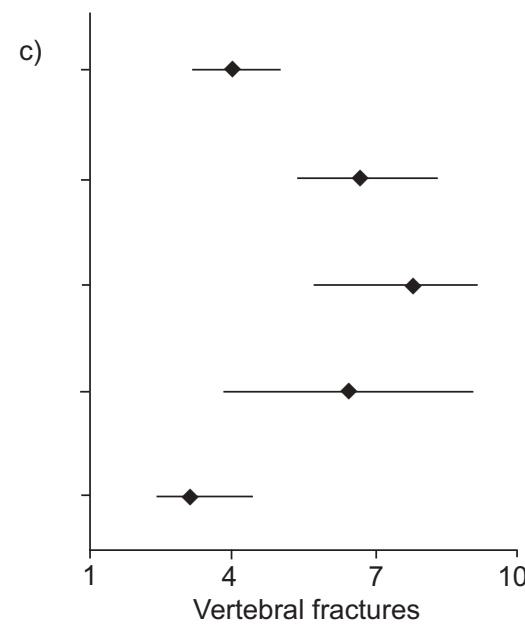

FIGURE 1. Crude odds ratios (95\% confidence interval) for fracture among patients with obstructive airway disease. \#: respiratory symptoms include bacterial respiratory tract infections, coughing, presence of sputum, haemoptysis, dyspnoea, tachypnoea, shortness of breath, acute bronchitis and wheezing.

fracture (crude OR 1.57; 95\% CI 1.49-1.67). Those who smoked $<20$ cigarettes $\cdot$ day $^{-1}$ had a crude OR of 1.57 (95\% CI 1.41-1.76) compared with an OR of 1.79 (95\% CI 1.24-2.57) in patients with OAD who smoked $>20$ cigarettes $\cdot$ day $^{-1}$. Among patients with a history of OAD, the risk of osteoporotic fracture was increased in both current (crude OR 1.53; 95\% CI 1.46-1.59) and past users (crude OR 1.36; 95\% CI 1.27-1.47) of inhaled corticosteroids, compared with those who had never used inhaled corticosteroids and were not diagnosed with OAD. Among the current users, the risk of fracture increased with daily dose (table 2). Patients exposed to bronchodilators also had an increased risk of fracture. When the current authors adjusted for general risk factors, bronchodilator use and indicators of disease severity, current use of inhaled corticosteroids was no longer associated with an increased risk of osteoporotic fracture (adjusted OR 1.04; 95\% CI 0.97-1.11). Furthermore, the dose response with inhaled corticosteroids observed in the crude analysis was no longer statistically significant. Current users of beclomethasone, budesonide or fluticasone had a comparable risk of fracture.

TABLE 2 Crude and adjusted odds ratios (OR) for fracture and use of inhaled corticosteroids and bronchodilators 6 months before the index date

\begin{tabular}{|c|c|c|c|c|c|c|c|c|}
\hline \multirow{2}{*}{$\begin{array}{l}\text { Fracture type and } \\
\text { average daily dose }\end{array}$} & \multicolumn{4}{|c|}{ Inhaled corticosteroids } & \multicolumn{4}{|c|}{ Bronchodilators } \\
\hline & Cases & Controls & Crude OR (95\% Cl) & Adjusted OR (95\% Cl) & Cases & Controls & Crude OR $(95 \% \mathrm{CI})$ & Adjusted OR $(95 \% \mathrm{Cl})$ \\
\hline Referent & & & 1.00 & 1.00 & & & 1.00 & 1.00 \\
\hline Osteoporotic & 108754 & 108754 & & & & & & \\
\hline $1-400 \mu g$ & 1747 & 1211 & $1.41(1.31-1.53)$ & $1.04(0.95-1.14)$ & 1650 & 1183 & $1.37(1.27-1.48)$ & $1.20(1.09-1.31)$ \\
\hline $401-800 \mu \mathrm{g}$ & 1571 & 1050 & $1.49(1.37-1.62)$ & $1.03(0.93-1.14)$ & 1606 & 976 & $1.70(1.57-1.85)$ & $1.45(1.32-1.60)$ \\
\hline $801-1600 \mu \mathrm{g}$ & 1367 & 788 & $1.77(1.61-1.93)$ & $1.15(1.03-1.29)$ & 1642 & 1091 & $1.57(1.45-1.70)$ & $1.28(1.16-1.41)$ \\
\hline$>1600 \mu \mathrm{g}$ & 512 & 281 & $1.95(1.68-2.27)$ & $1.19(1.01-1.41)$ & 1375 & 817 & $1.81(1.66-1.98)$ & $1.35(1.21-1.51)$ \\
\hline Hip & 14388 & 14388 & & & & & & \\
\hline $1-400 \mu \mathrm{g}$ & 188 & 139 & $1.36(1.08-1.71)$ & $1.01(0.76-1.34)$ & 203 & 157 & $1.29(1.04-1.61)$ & $1.20(0.94-1.55)$ \\
\hline $401-800 \mu \mathrm{g}$ & 212 & 164 & $1.29(1.04-1.59)$ & $0.97(0.74-1.28)$ & 257 & 153 & $1.75(1.42-2.16)$ & $1.58(1.22-2.04)$ \\
\hline $801-1600 \mu \mathrm{g}$ & 190 & 120 & $1.55(1.22-1.97)$ & $1.09(0.81-1.48)$ & 247 & 211 & $1.27(1.05-1.53)$ & $1.17(0.91-1.50)$ \\
\hline$>1600 \mu \mathrm{g}$ & 73 & 45 & $1.78(1.21-2.62)$ & $1.18(0.75-1.85)$ & 214 & 133 & $1.72(1.37-2.16)$ & $1.37(1.01-1.86)$ \\
\hline Vertebral & 8712 & 8712 & & & & & & \\
\hline $1-400 \mu \mathrm{g}$ & 205 & 84 & $2.61(2.00-3.39)$ & $1.60(1.14-2.24)$ & 168 & 101 & $1.80(1.39-2.32)$ & $1.03(0.75-1.43)$ \\
\hline $401-800 \mu \mathrm{g}$ & 209 & 85 & $2.71(2.07-3.55)$ & $1.33(0.93-1.90)$ & 199 & 84 & $2.72(2.08-3.57)$ & $1.32(0.94-1.86)$ \\
\hline $801-1600 \mu \mathrm{g}$ & 209 & 87 & $2.88(2.21-3.77)$ & $1.21(0.83-1.75)$ & 228 & 88 & $3.00(2.32-3.89)$ & $1.43(1.01-2.03)$ \\
\hline$>1600 \mu \mathrm{g}$ & 101 & 20 & $6.11(3.73-10.01)$ & $1.85(1.01-3.38)$ & 269 & 79 & $4.15(3.19-5.41)$ & $1.62(1.11-2.36)$ \\
\hline
\end{tabular}

$\mathrm{Cl}$ : confidence interval; referent crude OR: subjects who were never exposed to inhaled corticosteroids and who did not have a history of obstructive airway disease $(O A D)$; referent adjusted OR: subjects who were never exposed to inhaled corticosteroids and bronchodilators, and who did not have a history of OAD; adjusted: adjustments were made for general risk factors, smoking status, body mass index, duration of enrolment in the General Practice Research Database, indicators of OAD severity, and exposure to bronchodilators (inhaled corticosteroid group) or inhaled corticosteroids (bronchodilator group). 
Most current users of inhaled corticosteroids were also concomitantly exposed to bronchodilators (76\% for cases and $72 \%$ for controls). No statistically significant differences could be found between the use of both drugs at the same time and single use. In the high-dose group $(>1,600 \mu \mathrm{g}$ beclomethasone equivalents per day), approximately half had not been exposed to oral corticosteroids in the previous 6 months. These patients did not have an increased risk of osteoporotic fracture (adjusted OR 1.19; 95\% CI 0.96-1.47). The risk of fracture was increased in patients who were exposed to both oral corticosteroids and high-dose inhaled corticosteroids. For osteoporotic fracture, the adjusted OR was 1.79 (95\% CI 1.402.29), for hip fracture 1.77 (95\% CI 0.91-3.46), and 3.78 (95\% CI 1.79-7.97) for vertebral fracture. The median number of prior oral corticosteroid prescriptions was 14 in these patients.

As shown in table 3, patients with more severe OAD had higher risks of fracture, and these risks were comparable between users and nonusers of inhaled corticosteroids. The adjusted OR for osteoporotic fracture was 1.47 (95\% CI 1.25$1.74)$ in nonusers and $1.48(95 \%$ CI $1.29-1.71)$ in users of inhaled corticosteroids with more severe OAD.

\section{DISCUSSION}

In the current study, the association between exposure to high doses of inhaled corticosteroids and the risk of osteoporotic fracture was confirmed. Nevertheless, it was also found that the risk of fracture was related to indicators of severe OAD, and that patients using higher doses of bronchodilators also had increased risks of fracture. After adjustment for disease severity and use of bronchodilators, the initial association between use of inhaled corticosteroids and risk of osteoporotic fracture almost disappeared.

Two other studies, one using a case-control design and the other a cohort design, evaluated the risk of fracture of patients using inhaled corticosteroids in GPRD $[4,5]$. Both these studies found a dose-dependent increase in fracture risk, but they differed in their interpretation on the aetiology of this increased risk. The current authors were able to confirm the results of the case-control study [5] when the same definitions were applied (i.e. timing of prior use of inhaled corticosteroids was ignored by combining current and past users, and no adjustment was made for general risk factors, prior use of bronchodilators or disease-severity indicators, with the exception of oral corticosteroid use). However, when adjusting for disease-severity indicators, the hip-fracture risk in patients using inhaled corticosteroids was statistically comparable with nonusers, even at the higher doses. The present findings suggest an important role of the underlying respiratory disease in the aetiology of increased fracture risk.

There have been several studies that have evaluated the risk of fracture in users of inhaled corticosteroids. A case-control study conducted in Denmark found a nonsignificant trend between use of high-dose inhaled and intranasal corticosteroids and risk of hip fracture, but the authors did not adjust for comedication and severity indicators [7]. In a nested casecontrol study among elderly American veterans with COPD, a dose-response relationship between short-term use of inhaled corticosteroids and nonvertebral fracture risk was found. Adjustment for disease severity was limited to use of oral corticosteroids, the number of hospitalisations and the number of outpatient visits [6]. The importance of adjustment for the underlying disease severity was confirmed in a nested casecontrol study conducted in a Canadian population. Hipfracture risk was not associated with exposure to high-dose inhaled corticosteroids over a 4-yr period. The analysis was adjusted for the number of dispensings of bronchodilators [11]. In a cohort study consisting of Canadian females, exposure to inhaled corticosteroids was not associated with an increased risk of hip fracture. Results were adjusted for a wide range of underlying diseases, including a history of COPD [10].

The relationship between the use of inhaled corticosteroids and BMD was analysed in two meta-analyses, with inconsistent results. A Cochrane review of randomised clinical trials found no evidence for an effect of inhaled-corticosteroid exposure on BMD; however, the patient population included in the randomised trials had relatively mild respiratory disease and

\begin{tabular}{|c|c|c|c|c|c|c|c|c|c|c|}
\hline \multicolumn{2}{|c|}{ Patients with OAD } & \multicolumn{3}{|c|}{ Osteoporotic } & \multicolumn{3}{|c|}{ Hip } & \multicolumn{3}{|c|}{ Vertebral } \\
\hline Severe OAD \# & $\begin{array}{l}\text { Use of inhaled } \\
\text { corticosteroids }\end{array}$ & Crude OR & Adjusted OR" & $95 \% \mathrm{Cl}$ & Crude OR & Adjusted OR & $95 \% \mathrm{Cl}$ & Crude OR & Adjusted OR & $95 \% \mathrm{Cl}$ \\
\hline Yes & No & 1.84 & 1.47 & $(1.25-1.74)$ & 1.82 & 1.43 & $(0.87-2.35)$ & 3.43 & 1.83 & $(1.03-3.23)$ \\
\hline Yes & Yes & 1.92 & 1.48 & $(1.29-1.71)$ & 1.61 & 1.37 & $(0.87-2.15)$ & 4.69 & 2.57 & $(1.58-4.19)$ \\
\hline
\end{tabular}

Referent crude odds ratio (OR): subjects who were never exposed to inhaled corticosteroids and who did not have a history of OAD; referent adjusted OR: subjects who had never been exposed to inhaled corticosteroids and bronchodilators and who did not have a history of OAD; Cl: confidence interval. \#: severe disease was defined as the presence of one or more disease-severity indicators (exacerbation of OAD, use of oxygen in the previous 12 months, use of oral corticosteroids, body mass index $<20$, bacterial respiratory tract infections, coughing, presence of sputum, haemoptysis, dyspnoea, tachypnoea, shortness of breath, acute bronchitis and wheezing in the previous 6 months; $\because$ : adjusted for general risk factors, smoking status, duration of enrolment in the General Practice Research Database and exposure to bronchodilators. 
was young [22]. A meta-analysis, which also included observational studies, found that inhaled-corticosteroid users had, on average, a lower BMD than expected for their age and sex. To address the effect of confounding by underlying disease severity, RICHY et al. [23] classified studies on the basis of the type of controls to the inhaled-corticosteroid users: healthy population controls or controls with lung disease. It was found that inhaled-corticosteroid users had lower BMD in both sets of study populations and that these results were statistically similar. Nevertheless, the number of patients in the studies with healthy controls was quite small. Moreover, the largest differences between inhaled-corticosteroid users and controls were seen in the studies with healthy controls, although this was not statistically significant. In conclusion, this trend is consistent with the current hypothesis that underlying disease severity is important in the aetiology of reduced BMD in patients using inhaled corticosteroids [23].

The severity of pulmonary disease inversely correlated with BMD in three studies. An analysis of the Third National Health and Nutrition Examination Survey (NHANES) revealed that the risk of osteoporosis among males and females was inversely correlated with the degree of their airway obstruction. Adjustment for age, smoking, BMI, physical activity and different types of medication (among others, inhaled or oral corticosteroids, bronchodilators and oestrogens) did not change these results [13]. In a group of elderly Japanese females with COPD who were not exposed to oral corticosteroids, the prevalence of osteoporosis was $50 \%$, twice as high as a comparison group consisting of females of the same age with asthma [24]. A cross-sectional study in a general-practice setting among British females aged 45-76 yrs also showed an inverse relationship between forced expiratory volume in one second and BMD at the hip, which remained after adjustment for body weight and length. Although use of inhaled corticosteroids was not measured, the results remained similar after exclusion of patients who had a history of respiratory disease [12].

Several mechanisms have been suggested for this possible relationship between OAD and increased risk of fracture or osteoporosis. They include lack of physical activity [25, 26], low BMI among patients with COPD [27], smoking [28], a decreased exposure to sunlight [13], decreased testosterone levels [29], hypercapnia [30], and chronic inflammation. Cytokines that are expressed in inflammatory diseases, such as asthma and/or COPD, include tumour necrosis factor (TNF) $-\alpha$, transforming growth factor- $\beta$, interleukin (IL)- $1 \beta$, IL-4 and IL-8. These cytokines have been shown to affect bone remodelling in vivo and in vitro [31-37]. However, it is uncertain whether these cytokine levels are also increased in the osteoblasts and osteoclasts at the basic multicellular unit [38] in humans with respiratory disease. In a study among 68 post-menopausal females with osteoporosis, a correlation between levels of plasma IL- 8 or TNF- $\alpha$ and BMD was not found [39]. Many patients with OAD use $\beta_{2}$-agonists. The adrenergic pathway may play a role in the regulation of bone formation in ovariectomised mice [40]. The current authors stratified the bronchodilator group to $\beta_{2}$-agonists, antimuscarinics, xanthines, cromones and adrenoceptor agonists (e.g. ephedrine), and were unable to find a clear relationship between any class of drugs and risk of fractures. An interesting finding in the present study was an increased risk of fracture among past users of inhaled corticosteroids. This might be related to a history of concomitant oral-steroid use or a history of OAD.

This study has several limitations. Data on physical activity and smoking were limited. It is not obligatory for participating practices to record smoking status. The current data on smoking were incomplete, and the present results on the relationship between smoking and risk of fracture were lower than those recently reported in a meta-analysis [41]. There were no data on the loss of fat-free mass. Loss of fat-free mass has been associated with reduced BMD and more severe COPD, and might be a more concise marker of severity of OAD compared with BMI $[42,43]$. Although the current authors did not have data on BMI for all patients, the present finding of an inverse relationship between BMI and fracture risk was consistent with those previously reported [44, 45]. Controlling for severity of the underlying disease could also be improved with spirometry data, which were not available in this study. Lastly, among the patients who used $>1,600 \mu \mathrm{g}$ beclomethasone equivalents per day, a large number $(46 \%)$ were using oral corticosteroids (median number of oral-corticosteroid prescriptions was 14). Therefore, it may be difficult in this patient group to separate the effects of oral and inhaled corticosteroids.

In conclusion, patients using higher doses of inhaled corticosteroids have an increased risk of osteoporotic fracture. However, patients using bronchodilators and those with more severe obstructive airway disease also have an increased risk of fracture, and the dose-response relationship between inhaled corticosteroids and fracture risk almost disappears after adjustment for disease severity. Consequently, adequate adjustment for disease severity is essential when the association between use of inhaled corticosteroids and risk of fracture is studied in observational research.

\section{REFERENCES}

1 Lanes SF, Garcia Rodriguez LA, Huerta C. Respiratory medications and risk of asthma death. Thorax 2002; 57: 683-686.

2 Martin RJ, Szefler SJ, Chinchilli VM, et al. Systemic effect comparisons of six inhaled corticosteroid preparations. Am J Respir Crit Care Med 2002; 165: 1377-1383.

3 Van Staa TP, Leufkens HG, Abenhaim L, Zhang B, Cooper C. Use of oral corticosteroids and risk of fractures. J Bone Miner Res 2000; 15: 993-1000.

4 Van Staa TP, Leufkens HG, Cooper C. Use of inhaled corticosteroids and risk of fractures. J Bone Miner Res 2001; 16: $581-588$.

5 Hubbard RB, Smith CJ, Smeeth L, Harrison TW, Tattersfield AE. Inhaled corticosteroids and hip fracture: a population-based case-control study. Am J Respir Crit Care Med 2002; 166: 1563-1566.

6 Lee TA, Weiss KB. Fracture risk associated with inhaled corticosteroid use in chronic obstructive pulmonary disease. Am J Respir Crit Care Med 2004; 169: 855-859.

7 Vestergaard P, Olsen ML, Paaske Johnsen S, Rejnmark L, Sorensen HT, Mosekilde L. Corticosteroid use and risk of hip fracture: a population-based case-control study in Denmark. J Intern Med 2003; 254: 486-493. 
8 Suissa S. Possible sources of bias in observational studies of the effectiveness of inhaled corticosteroids in COPD. Eur Respir J 2003; 22: Suppl. 43, 9s-12s.

9 van Staa TP, Leufkens B, Cooper C. Bone loss and inhaled glucocorticoids. N Engl J Med 2002; 346: 533-535.

10 Lau E, Mamdani M, Tu K. Inhaled or systemic corticosteroids and the risk of hospitalization for hip fracture among elderly women. Am J Med 2003; 114: 142-145.

11 Suissa S, Baltzan M, Kremer R, Ernst P. Inhaled and nasal corticosteroid use and the risk of fracture. Am J Respir Crit Care Med 2004; 169: 83-88.

12 Lekamwasam S, Trivedi DP, Khaw KT. An association between respiratory function and bone mineral density in women from the general community: a cross sectional study. Osteoporos Int 2002; 13: 710-715.

13 Sin DD, Man JP, Man SF. The risk of osteoporosis in Caucasian men and women with obstructive airways disease. Am J Med 2003; 114: 10-14.

14 van Staa TP, Leufkens HG, Cooper C. Inhaled corticosteroids and hip fracture: disease or drugs? Am J Respir Crit Care Med 2003; 168: 128-129.

15 Walley T, Mantgani A. The UK General Practice Research Database. Lancet 1997; 350: 1097-1099.

16 van Staa TP, Abenhaim L, Cooper C, et al. The use of a large pharmacoepidemiological database to study exposure to oral corticosteroids and risk of fractures: validation of study population and results. Pharmacoepidemiol Drug Saf 2000; 9: 359-366.

17 Hollowell J. General Practice Research Database (GPRD): Scope and Quality of Data. London, Office of Population Censuses and Statistics, 1994.

18 van Staa TP, Wegman S, de Vries F, Leufkens B, Cooper C. Use of statins and risk of fractures. JAMA 2001; 285: 1850-1855.

19 Soriano JB, Maier WC, Visick G, Pride NB. Validation of general practitioner-diagnosed COPD in the UK General Practice Research Database. Eur J Epidemiol 2001; 17: 1075-1080.

20 British National Formulary. Vol. 37. London, British Medical Association, 1999.

21 Anonymous. ATC classification index with DDDs 2002. Nydalen, WHO Collaborating Centre for Drug Statistics Methodology, Norwegian Institute of Public Health, 2002.

22 Jones A, Fay JK, Burr M, Stone M, Hood K, Roberts G. Inhaled corticosteroid effects on bone metabolism in asthma and mild chronic obstructive pulmonary disease. Cochrane Database Syst Rev 2002; 1: CD003537.

23 Richy F, Bousquet J, Ehrlich GE, et al. Inhaled corticosteroids effects on bone in asthmatic and COPD patients: a quantitative systematic review. Osteoporos Int 2003; 14: 179-190.

24 Katsura H, Kida K. A comparison of bone mineral density in elderly female patients with COPD and bronchial asthma. Chest 2002; 122: 1949-1955.

25 Malkia E, Impivaara O. Intensity of physical activity and respiratory function in subjects with and without bronchial asthma. Scand J Med Sci Sports 1998; 8: 27-32.

26 Ford ES, Heath GW, Mannino DM, Redd SC. Leisure-time physical activity patterns among US adults with asthma. Chest 2003; 124: 432-437.

27 Incalzi RA, Caradonna P, Ranieri P, et al. Correlates of osteoporosis in chronic obstructive pulmonary disease. Respir Med 2000; 94: 1079-1084.
28 Ward KD, Klesges RC. A meta-analysis of the effects of cigarette smoking on bone mineral density. Calcif Tissue Int 2001; 68: 259-270.

29 Kamischke A, Kemper DE, Castel MA, et al. Testosterone levels in men with chronic obstructive pulmonary disease with or without glucocorticoid therapy. Eur Respir J 1998; 11: 41-45.

30 Dimai HP, Domej W, Leb G, Lau KH. Bone loss in patients with untreated chronic obstructive pulmonary disease is mediated by an increase in bone resorption associated with hypercapnia. J Bone Miner Res 2001; 16: 2132-2141.

31 Lam J, Takeshita S, Barker JE, Kanagawa O, Ross FP, Teitelbaum SL. TNF-alpha induces osteoclastogenesis by direct stimulation of macrophages exposed to permissive levels of RANK ligand. J Clin Invest 2000; 106: 1481-1488.

32 Jilka RL, Weinstein RS, Bellido T, Parfitt AM, Manolagas SC. Osteoblast programmed cell death (apoptosis): modulation by growth factors and cytokines. J Bone Miner Res 1998; 13: 793-802.

33 Hock JM, Krishnan V, Onyia JE, Bidwell JP, Milas J, Stanislaus D. Osteoblast apoptosis and bone turnover. J Bone Miner Res 2001; 16: 975-984.

34 Boyle WJ, Simonet WS, Lacey DL. Osteoclast differentiation and activation. Nature 2003; 423: 337-342.

35 Chung K. Cytokines. In: Barnes P, Drazen J, Rennard S, Thompson N, eds. Asthma and COPD. Basic mechanisms and clinical management. London, Academic Press, 2002.

36 Okada Y, Morimoto I, Ura K, et al. Short-term treatment of recombinant murine interleukin-4 rapidly inhibits bone formation in normal and ovariectomized mice. Bone 1998; 22: 361-365.

37 Bendre MS, Montague DC, Peery T, Akel NS, Gaddy D, Suva LJ. Interleukin-8 stimulation of osteoclastogenesis and bone resorption is a mechanism for the increased osteolysis of metastatic bone disease. Bone 2003; 33: 28-37.

38 Frost HM. Tetracycline-based histological analysis of bone remodeling. Calcif Tissue Res 1969; 3: 211-237.

39 Sahin G, Ozturk C, Bagis S, Cimen OB, Erdogan C. Correlation of serum cytokine levels with axial bone mineral density. Singapore Med J 2002; 43: 576-578.

40 Takeda S, Elefteriou F, Levasseur R, et al. Leptin regulates bone formation via the sympathetic nervous system. Cell 2002; 111: 305-317.

41 Kanis JA, Johnell O, Oden A, et al. Smoking and fracture risk: a meta-analysis. Osteoporos Int 2005; 16: 155-162.

42 Ionescu AA, Evans WD, Pettit RJ, Nixon LS, Stone MD, Shale DJ. Hidden depletion of fat-free mass and bone mineral density in adults with cystic fibrosis. Chest 2003; 124: 2220-2228.

43 Bolton CE, Ionescu AA, Shiels KM, et al. Associated loss of fat free mass and bone mineral density in chronic obstructive pulmonary disease. Am J Respir Crit Care Med 2004; 170: 1286-1293.

44 Johnell O, Gullberg B, Kanis JA, et al. Risk factors for hip fracture in European women: the MEDOS Study. Mediterranean Osteoporosis Study. J Bone Miner Res 1995; 10: 1802-1815.

45 Roy DK, O’Neill TW, Finn JD, et al. Determinants of incident vertebral fracture in men and women: results from the European Prospective Osteoporosis Study (EPOS). Osteoporos Int 2003; 14: 19-26. 